\title{
Acção/Investigação em Educação Artística: em busca de uma narrativa renovada, implicada na construção pertinaz de uma democracia agonística
}

Acción/Investigación en Educación Artística: la búsqueda de una narrativa renovada, que participan en la construcción de una democracia agonística persistente

Action/Research in Art Education: seeking a renewed narrative, involved in the construction of a persistent agonistic democracy

\author{
José Carlos de Paiva \\ jpaiva@fba.up.pt \\ i2ADS - Instituto de Investigação em Arte Design e Sociedade - núcleo de Educação Artísti- \\ ca; Faculdade de Belas Artes da Universidade do Porto
}

\section{RESUMO}

"Nó e labirinto tornam-se assim a imagem estrutural do próprio saber: um saber aberto interdisciplinar, em movimento, sempre sujeito ao risco da perda de orientação."

CALABRESE (1987:151/2)

Nos tempos em que vivemos, na afirmação de uma pertença ao contemporâneo que vincula a implicação da produção (pensamento/acção) ao social, questiona-se a natureza do ímpeto de um professor/artista/investigador, ao se envolver na 'investigação em educação artística'?

O artigo escreve-se no quadro assumido pelo autor, do sentido do político, intrínseco ao cultural, a partir do qual se questionam os fundamentos de onde emergem as práticas de acção/investigação. Nesse quadro percorrem-se as possibilidades de renovação das narrativas sobre 'educação artística' de modo a se explicitar a sua imprescindibilidade social na construção de sujeitos, determinadas a partir de cada um, face às confrontações sociais que lhes são relacionais, e a promover a experienciação de posturas partilhadas de afirmação crítica perante os valores hegemónicos, efectivando práticas agonísticas de desconstrução dos valores culturais e sociais dominantes e de explicitação de utopias.

A natureza particular do 'artístico' é tratada como essência marcante da 'investigação em educação artística', moldando-Ihe o sentido e os processos, onde a utilização de matrizes usuais das 'ciências humanas', das 'ciências da educação', das 'ciências da arte', não Ihes fornecem as possibilidades suficientes de produção de acção/pensamento. Procura-se, assim, entender a urgência da ampliação do debate existente para uma afirmação social de outros modos de investigação, para a utilização das linguagens que são próprias e naturais no terreno intersubjectivo e relacional onde se move a 'educação artística'.

Palavras-chave: educação artística, arte, educação, acção/investigação; político 


\section{RESUMEN}

"Nó e labirinto tornam-se assim a imagem estrutural do próprio saber: um saber aberto interdisciplinar, em movimento, sempre sujeito ao risco da perda de orientação."

CALABRESE (1987:151/2)

En los tiempos en que vivimos, formando parte de lo contemporáneo que se vincula a las implicaciones de la producción (pensamiento / acción) al social, ¿se cuestiona la naturealeza del impulso de un profesor / artista / investigador para involucrarse en la "investigación en educación artística"?

El artículo está escrito bajo el enmarco del sentido de lo político tomado por el autor, intrínseco a la cultura, dónde se cuestionan las bases de las cuales surgen las prácticas de acción / investigación. En ese enmarco se manifiesta el recorrido de las posibilidades de renovación de las narrativas sobre "educación artística", de modo que queda claro su importancia social en la construcción de sujetos, determinadas a partir de cada uno, ante el enfrentamiento social inherente y a promover la experimentación de posturas de afirmación crítica con respecto a valores hegemónicos, llevando a cabo prácticas agonísticas de la deconstrucción de valores culturales y sociales dominantes, expresando utopias.

La naturaleza particular de lo " artístico" se considera como elemento central de la "investigación en educación artística", dando forma a su sentido y a sus procesos, donde la utilización de las matrices de las usales "ciencias humanas", de las "ciencias de la educación", de las "ciencias del arte", no les dan la suficiente posibilidad para la producción de acción / pensamiento. Se busca, así, entender la urgencia de ampliar el debate existente para una afirmación social de otros modos de investigación, para el uso de los lenguajes que les son propios y naturales en el campo relacional e intersubjetivo donde recorre la "educación artística".

Palabras-clave: educación artística, arte, educación, acción/investigación; político 


\section{ABSTRACT}

"Nó e labirinto tornam-se assim a imagem estrutural do próprio saber: um saber aberto interdisciplinar, em movimento, sempre sujeito ao risco da perda de orientação."

CALABRESE (1987:151/2)

In the times we live in, which belong to the contemporary that links the implications of production (thought / action) to the social, to what corresponds the impetus of a teacher / artist / researcher to be engaged with 'arts education research'?

The direction taken by the author of this article is politically assumed, intrinsic to the cultural, where the foundations of the practices of action / research are questioned. This is the framework that offers the possibility for renewing 'arts education' narratives in order to explain their indispensability in the construction of social subjects, through the confrontations that are relational to them, and to promote the affirmation of a shared critical positioning towards the hegemonic values, activating agonistic practices of deconstruction facing the cultural and social dominant values as well as the explanation of utopias.

The specific nature of the 'artistic' is treated as core feature of 'research in art education', shaping its meaning and processes, but where the use of models coming from the 'human sciences', the 'sciences of education', or the 'science of art', not provide this kind of research with enough opportunities to produce action / thought. Therefore, we seek to understand the need for expanding the existing debate to social statement that opens up to other ways of research, by using languages that more appropriate to the relational and intersubjective field where 'art education' inhabits.

Keywords: art education, art, education, action / research; political 
Aquele que pertence deveras ao seu tempo, que é deveras contemporâneo é alguém que não coincide perfeitamente com ele nem se adapta às suas exigências e é por isso, nesse sentido, inactual; mas, precisamente por isso, precisamente através do seu distanciamento e do seu anacronismo, é capaz de perceber e captar o seu tempo melhor que os outros.

AGAMBEN (2009:20)

\section{. ZERO - INVESTIGAR?}

Os cataclismos financeiros actuais tornam mais visível a injustiça reinante onde os detentores do poder financeiro nunca perdem o controle sobre as suas regalias e desvalorizam a perda generalizada de 'direitos', o empobrecimento dos 'outros' e mesmo a exclusão das possibilidades de sobrevivência decente de milhares de cidadãos, de nomes ignorados, sem emprego, sem terra, sem sonho.

Vivemos neste tempo, metidos numa incrível mercantilização da sociedade, dominadora dos desejos, neste mundo paranóico, condicionador das comunidades que hão-de vir - AGAMBEN (1990). E nele, a arte se o questiona ao se questionar a si própria, não se afasta dele, na impossibilidade de passagem de um terreno desfronteirizado para um isolamento tranquilo, e não deixa de nele ser pertença de uma cultura hegemónica, em que a presença de posturas radicais são empurradas para o ostracismo. "En la sociedad de consumidores no tienen cabida los consumidores fallidos, incompletos o frutados". BAUMAN (2004:27)

A educação liberta um amplo campo de possibilidades para que cada pessoa se possa construir na singularidade da sua relação de pertença social, mas não deixa de se mover entre a formatação reprodutora e utilitarista que os seguidores dos saberes e valores vigentes fomentam, e a experienciação de inquietude e desconstrução das narrativas dominantes que a insatisfação e o discernimento geram. "El problema principal que hoy tienen nuestras escuelas y universidades es la narrativa dominante sobre la educación en la que se inscriben y en su dificultad de cambiarla."

HERNANDEZ (2007: 9)
As Universidades encurraladas pelos acordos governamentais de Bolonha, afogam os seus docentes em trabalho lectivo sem fim, orientações de dissertações e teses em massa, e responsabilizam-os pela superação das restrições de tesouraria que a desorçamentação da política ultraliberal lhes apresenta. A investigação classificada de imperiosa nos processos de avaliação interna e externa, e fonte de rendimento salvador para as instituições, move-se em superfícies lodosas, indefinidas e de efémero enquadramento, atraídas entre a tradição académica, a eficácia instrumental ao serviço da 'indústria' e a produção de uma 'economia do saber'. Os padrões de avaliação determinam-se pelos marcos do emprendedorismo, da aplicabilidade produtiva dos resultados e não se moldam às particularidades dos campos de subjectividade de áreas particulares. O poder dominante quer produtividade, ostentação de saberes, reprodução dos valores hegemónicos que reproduzam as condições de governabilidade e desenvolvimento do modelo económico que lhe dá sustentação e possibilidades especulativas aos 'mercados'.

Não ignorar as encruzilhadas dos tempos e dos espaços que se apresentam, numa actualidade desconfiada de si própria, só pode corresponder a um posicionamento no político MOUFFE (1993), esclarecimento do sentido de quem quer agir, na cultura, na arte na educação e/ou na investigação.

\section{. PRIMEIRO - INVESTIGAR}

"Lo político tiene que ver con la dimensión del antagonismo presente en las relaciones sociales, con la posibilidad siempre presente de que la relación 'nosotros/ellos' se construya en términos de 'amigo/enemigo'."

MOUFFE (2007:18)

Este artigo não resulta de um impulso inócuo de apresentação do que se pode entender hoje da 'investigação em educação artística'. Declaradamente, afirma uma postura implicada com o tempo, inscrita no político, esclarecimento do seu registo no artístico, no educativo, e na procura de uma acção complexa que construa um quadro epistemológico esclarecedor da imprescindibilidade de uma educação 
artística promotora de novas relações dos sujeitos, e de práticas agonísticas de desconstrução dos valores culturais e sociais hegemónicos. Evoca-se a necessidade de legitimar o espaço desordeiro onde se assuma o 'conhecimento naturalizado' como discutível e se afirme essa urgência. "Todos os que frequentam a universidade sabem que o sistema educacional funciona através da recompensa à obediência e à conformidade; se não encaixamos no molde, somos desordeiros. Deste modo, trata-se de um género de mecanismo de filtragem que dá origem a pessoas (não estão a mentir) que interiorizam a estrutura de crenças $e$ de atitudes do sistema de poder envolvente na sociedade." CHOMSKY, Noam (2008). In, MACEDO (2011: 83).

A angústia do tempo anuncia a urgência de uma acção persistente em busca de uma narrativa renovada, da construção pertinaz de uma democracia agonística MOUFFE (2007), que permita e promova acções educativas e artísticas radicais, que possibilitem aos que hão-de vir, a construção de suas vidas sociais, a construção das representações próprias de cada sujeito, e não lhe determine e pré-configure o sentido de existência.

Sem desvalorizar o valor que as investigações trazem em si, e as teses desenvolvidas pelas 'ciências da educação' e pelas 'ciências da arte', mesmo se incapazes de quaisquer reconfigurações metodológicas perante a natureza do 'fazer artístico', defende-se aqui a concentração de esforços dos professores/artistas/investigadores na procura de outras narrativas que, alojadas nas possibilidades de acção experiencial, na dimensão em que o artístico implica sempre o 'fazer' e que o educativo representa de 'movimento relacional', evidenciem a imprescindibilidade da educação artística no deslindar das encruzilhadas do tempo, no reencontro das pessoas com o seu potencial crítico e constitutivo de outros tempos. Manter a ambiguidade de uma 'educação artística' fundamentada em premissas do modernismo e do racionalismo, em perseguições românticas do papel libertador da arte, e do valor dominante da expressão e da criatividade, não permite actualizar este privilegiado campo educativo aos conturbados tempos que vivemos, aproximando-a das posturas artísticas contemporâneas, das controvérsias actuais das práticas artísticas, da presença do artístico no espaço público, das novas problemáticas alargadas ao campo da cultura visual, dos impulsos culturais de grupos sociais anteriormente sem presença, das dinâmicas emancipadoras de comunidades. Nem é suficiente o se promover a essencial mudança das práticas educativas, ultrapassando os quadros teóricos construídos pelas ciências da educação, para a efectivação de novas relações educativas, nos contextos precisos onde operam, perante os intervenientes nomeáveis, face a abordagens efectivas dos campos de saber, perante a aceitação das derivas próprias da epistemologia e, de facto, no respeito pelos sujeitos enquanto responsáveis e decisores de suas vidas. E, assim, tornar relevantes os resultados ensaiados da investigação contemporânea que perseguem outras narrativas, Ihes configuram um sentido validado na acção e se configuram de modo endógeno à natureza particular do território epistemológico da educação artística, do artístico, e da acção educativa.

\section{. SEGUNDO - INVESTIGAR?}

“(...) arte, pesquisa e ensino não são feitos, mas vividos."

FREIRE (1996:97)

Toma-se aqui como referência que o investigador em educação artística, dispõe de maior completude se emana de um professor/artista/investigador, não desclassificando as competências de outras entidades, nem negando as vantagens de se manterem as porosidades existentes. Um professor pode não ser um investigador, embora seja fundamental uma inscrição sua na categoria de 'professor reflexivo' (Schön:1987) para uma actividade não rotineira e atenta ao desenvolvimento das relações educativas que se estabelecem. Assim como um artista pode não ser investigador e isso em nada desvaloriza as suas criações.

Entendendo a investigação em 'educação artística' como um campo epistemológico e ontológico singular, considerem-se os professores/artistas numa fundida proximidade, ou num posicionamento de ocupação desse espaço uno e singular, e se estabelecem as condições próprias para a produção de conhecimento 'em' educação artística, onde se pode realizar, 
por excelência, um discurso que anule as possibilidades de se transferir para a 'tradução' o que é intraduzível (a arte, essência da educação artística) e, assim, investigar pelo seu próprio prazer, pela riqueza especulativa que comporta, pela desnecessidade de justificação, pela sua obsolescência. "Não se deve entender a logofobia como a admissão ou desistência de discursar sobre a obra, mas a consciência do exercício dessa dificuldade." DIAS, Fernando Paulo Rosa, 'Poesis' e 'logos' - estratégias de relação entre o discurso e a produção artística no âmbito de uma investigação em arte, in CIEBA (2011:83)

Perante a autonomia conquistada no terreno da 'arte' (Art-Based Research, Art Practice as Research, Praticeled Research, Research-led Practice in Creative Arts) e da 'educação artística' (investigação das didácticas de currículo escolar, Research in Education in Art \& Design, Artes y Educación, Arts-Based Educational Research, Las metodologías artísticas de investigación en educación MAIE, $A / R / T$ /ography) existem possibilidades diversas para se encontrarem e construirem métodos e categorias de investigação próprias, que libertem a reflexão, a análise e a produção de pensamento das amarras metodológicas das 'ciêncas da arte', das 'ciências da educação', considerando que "...existem outros modelos para a actividade investigadora para além do científico" (FERRÃO, Hugo, Narrativas rizomáticas, velhos e novos paradigmas investigativos na FBAUL, in CIEBA (2011:50).

Sublinhada a pertença matricial e vinculativa da arte na educação artística, pela singularidade que a arte comporta, onde o que acontece é único e irrepetível, sempre excepção e nunca regra, e estabelecida a imprescindibilidade de fusão da investigação com o 'fazer artístico', com o campo dialogante que à obra é imanente, interessa voltar a colocar a questão inicalmente aflorada e que alimenta o interesse e o investimento na investigação. Assim, quando se discute a 'investigação em educação artística', e em 'arte', e se a encara como um devir, não pode deixar de se questionar o 'ponto de partida', mobilizador dos impulsos e das atitudes que argumentam o interesse pela investigação, que esclarecem a sua finalidade e estabelecem os processos a realizar:
- trata-se de um processo de construção epistemológico de saberes sobre o existente, que se encerra no conhecimento produzido?;

- trata-se de um estudo narcisista, de investigação onde o sujeito é o objecto de investigação? Ou um estudo onde o investigador se implica por actor da acção envolvida na investigação?;

- será a busca da renovação dos saberes, a possibilitação de novas práticas e reenquadramento das existentes?;

- trata-se de uma análise sobre um mundo externo à investigação? ou pretende-se uma investigação capaz de configurar especificidades identificativas?;

- será a leitura de resultados e potencialidades da experienciação e da procura inventiva de acções interventivas nos contextos precisos onde se promovem acções educativas, ou artísticas, decorrentes dos interesses dos seus actores?...

“(...) sublime, na sua maneira particular, é de facto o sentir revolucionário (...)"

PERNIOLA (1991:78)

Neste artigo defende-se que, mais do que a escolha de metodologias e de processos de estruturação e de esclarecimento da acção, é no posicionamento sincero em cada um dos investigadores perante o seu 'tempo', na sua implicação e procura de uma acção contaminadora para o seu 'produto' e a sua 'obra', que se deve encontrar o devir que a legitima. A investigação resulta de uma determinação de busca de um conhecimento crítico perante os redutores e naturalizados discursos que se difundem, e pode não ser apenas a resposta a um ímpeto de empregado, que produz porque essa é a sua profissão, ou condição académica, ou porque 'tem de ser', mas antes essa outra ocupação de um espaço de entendimento implicado na acção educativa e cultural, que se pretende alimento de estudo, produtora de pensamento e promotora de mudança. Mudança que persiga as narrativas de construção de uma democracia radical, que clame uma presença agonística no tempo, e não no sentido caduco da proclamação de qualquer construção 
de um homem novo, criativo, competente e empreendedor, mas outrossim, na criação de possibilidades para que cada sujeito se construa a partir de si, como cidadão empenhado no esclarecimento da sua pertença social. Não se trata aqui de promover um estado missionário, de sentido doutrinário, mas apenas de vincular para a investigação o mesmo estatuto social do artístico e do educativo, entendidos numa plataforma democrática agonística de promoção de práticas autorais e de acção educativa, libertadoras de um 'aberto' - AGAMBEN (2002), em que os sujeitos ganham espaço para elaborarem a 'escrita de si' - FOUCAULT (1992) em presença crítica face aos valores hegemónicos dominantes.

A entidade evocada como sujeito privilegiado da investigação em educação artística, (professor/artista/investigador), apenas acrescenta uma disponibilidade assumida para uma acção globalizante, que não isola as pertenças ao diverso, mas mobiliza a amplitude do conhecimento construído para o 'fazer' educativo e artístico, explicitando a arte como mãe, estendendo o devir profissional dos educadores para a implicação no político de que a arte contemporânea não prescinde, em amplitudes que comportam a sua obsolescência.

A 'investigação em educação artística' pode ser efectivada por quem a ela se dedicar, no entanto, a impossibilidade de fraccionar ou fragmentar a 'acção artística/educativa' endossa uma responsabilidade acrescida de complexidade que adquire a sua amplitude no quadro do 'ensino artístico', espaço dedicado ao diálogo entre o 'fazer artístico' e a produção de linguagem, na presença reflexiva sobre a prática artística. Neste espaço privado, do pensar sobre o fazer e do próprio fazer, isolam-se as tentações de tradução e de interpretação e aceitam-se as demandas experienciais e especulativas que lhe são próprias, bem como de aceder a uma consciência da impossibilidade de conhecimento completo, por se inscrever a arte na procura permanente de outras referências, disponíveis para todos os desvios e carente de novas experiências.
"Quando reduzimos a obra de arte ao seu conteúdo e depois interpretamos isso, domamos a obra de arte. A interpretação torna a obra de arte maleável, dócil."

SONTAG (1966:16)

Se a investigação em arte transfere a necessidade de se tornar dialogante de qualquer outra área, não deixa de se vincular a um campo particular onde esse diálogo se torna frutuoso, nem abandona a natureza peculiar que a circunscreve. Tratando-se de conformar o espaço da investigação em educação artística, não se poderá deixar de invocar a imanência da obra de arte, o campo de possibilidades educativas que toda a obra exala, a partir de si, promovida em contextos expositivos e museológicos, mediada por críticos, curadores, serviços educativos, jornalistas e demais agentes culturais. E esta é uma superfície infindável que integra a educação artística e lhe completa o sentido.

Não sendo este o espaço para um trabalho que nomeie os sítios de problematização da investigação em educação artística, e escrevendo-se este artigo a partir da matriz pessoal de um professor/artista/investigador nascido nas artes visuais, o que lhe determina onde se coloca o pontode-vista, não deveria deixar de se referir a natureza nãodisciplinar da educação artística, inclinada por vezes para áreas disciplinares (da música, do teatro, da perfomance, ...), ou trilhando terrenos interrelacionais, híbridos ou sem fronteira. Nem deveria, na actualidade onde o formalismo visual deixou de ser fulcral, de se evocar a pertinência do campo da cultura visual e o modo como este espaço invade toda a educação artística, na mesma proporção de como a imagem nos invade o quotidiano e nos obriga a sobre ela saber pensar, tornando crítica nossa postura perante a cultura hegemónica que quer afogar nossa vinculação a ter uma voz, a tecer cumplicidades e solidariedades com quem quer ter uma voz agonística na sociedade que nos amargura. 


\section{. TERCEIRO - INVESTIGAR}

"As universidades parecem quase que funcionam como a política, ou como os políticos - vivem a pensar e a reflectir sobre o mundo, mas como se o mundo fosse dentro das suas paredes."

FRAGATEIRO, Fernanda (2005). entrevista, in Nexus, 00, Porto, 2007. p. 17

Naturalmente, a discussão sobre 'investigação em educação artística' e em 'arte' não se remete à pré-questão supraevocada, nem às tensões da arte no cerne da sua produção, a discussão tem de esclarecer a natureza ampla da matéria sempre plena de intersubjectividade onde se move, (arte, educação, cultura visual, desenvolvimento). Tratar a 'educação artística' como um território de ramificações disciplinares múltiplas, que não se contenta na evocação das 'ciências da educação' e do 'artístico', nem na sua soma, que a distingue como um campo epistemológico e entológico singular, não impede o estabelecimento da 'arte' como seu foco, entendendo que é no esforço da arte se pensar a si própria, na capacidade de suspensão que domina, nessa procura de processos peculiares de produção de pensamento, que reside a essência do carácter particular desta área de acção/investigação. A pertença à 'educação' tem o seu esplendor num campo particular, preciso, distinto das ciências da educação, por se lhe precisar um conteúdo que pela sua natureza vírica as contamina. E nesse sentido, não lhe negando a autoridade e o campo de possibilidades de the engrandecer o sentido e possibilidades de globalizar o estudo, considera-se ser de um terreno outro que se trata, próprio, onde a 'educação artística' funde-se no 'artístico', âmago que nela se entranha como seu ente. (...) o que está em jogo é a libertação total relativamente a modos de pensamento e de expressão preestabelecidos, com vista à promoção necessária de maneiras de sentir e dizer especificamente novas, cuja procura implica, por definição, o máximo de aventura. BRETON (1952: 46). Esta promíscua e incestuosa relação amarra a natureza da 'educação artística' à intersubjectividade da 'arte' e do seu devir, e alarga-se à dimensão social e cultural da educação.
"O educador democrático não pode negar-se o dever de, na sua prática docente, reforçar a capacidade crítica do educando, sua curiosidade, sua insubmissão."

FREIRE (1996: 33)

E prende-a à contemporaneidade, plano onde a arte se enfrenta na transgressão perante ela própria, desprendida da necessidade de se tornar novidade e instrumento, e incómoda ao enfrentar a permissividade ao hegemónico e em suspender a entrega à atractividade sedutora ao poder que the oferece o espectacular palco de suas instituições. No sistema se constroem as alternativas e se apresentam as contradições, se disputam as representações intersubjectivas dos sujeitos e das comunidades.

“(...) la creación de una hegemonía y ver por qué los artistas pueden desempeñar un papel importante en la subversión de la hegemonía dominante. En nuestras posdemocracias, en las que celebra un consenso pospolítico como gran avance para la democracia, las praticas artísticas críticas pueden desbaratar la imagen agradable que el capitalismo de las grandes empresas está intentando difundir, al situar en primer plano su carácter represivo, y también pueden contribuir, de muy diversas formas, a la construción de nuevas subjectividades. Esa es la razón por la que las considero una dimensión decisiva del proyecto democrático radical."

MOUFFE (2007:70)

Pretende-se tornar claro que se entende a investigação como um campo de produção de conhecimento, um espaço de construção metodológica de um saber que se oferece publicamente, soltando uma emanação contaminante. Fomenta-se um diálogo público entre os intervenientes implicados na investigação, ampliam-se relações interpessoais e societais, confrontam-se campos do fazer e da busca do inalcançável, procura-se agir. "(...) ao trazer à luz os movimentos do pensamento, dissipa a sombra interior onde se tecem as tramas do inimigo." FOUCAULT (1969:131) 
. QUARTO - INVESTIGAR?

"A análise de qualquer obra plástica mostrará que ela desconhece qualquer outra maneira de produzir as afirmações que são específicas do seu meio."

ROTHKO (2007:127)

Os dilemas da 'investigação em educação artística' estão neste artigo evocados, na consciência de que merecem tratamentos mais completos e diversos, que fomentem a necessária controvérsia geradora de maior discernimento, actualidade e efectivação. A história da investigação em educação artística é reduzida, e demasiado circunscrita a grupos pouco relacionados entre si, ainda que se registem esforços consideráveis pela inversão deste panorama. Urge alastrar o campo desta discussão para lá das fronteiras de cada grupo isolado que constrói a sua própria experiência, nas lacunas que o isolamento sempre comporta.

"Mas quase cinquenta anos de experiência de culturas de complexidades extremamente diversas convenceram-me de que o Ocidente cometeu um grande erro ao recusar considerar os conhecimentos e capacidades muito particulares desenvolvidos noutras culturas, apenas porque elas não são conformes aos nossos modelos científicos. Temos muito a aprender do estudo das outras culturas." HALL (1983: 105)

De onde escrevo, a concentração nesta área é recente e diminuta, inscrita num esforço de relacionamento intercontinental de onde se esperam colher ensinamentos. De qualquer modo, na cidade do Porto (Portugal), o impulso de um pequeno grupo de investigadores semeia possibilidades, escolhe-se um caminho, privilegia-se a acção/ investigação, fomenta-se a convocação de professores/ artistas/investigadores para um modelo de investigação participativo, implicados na acção, procurando uma consciência de si, actores sociais. Procura-se um campo de implicação, não a constituição de uma 'classe especializada' distanciada, mas envolvida com os 'participantes na acção', constituídos por entidades singulares com voz e presença agonística. Que o esforço não estabeleça nem procure uma neutralidade celebratória, alojada em terrenos confortáveis onde os investigadores usem 'luvas e máscaras' para não contaminarem nem serem contaminados no que acontece (Paulo Freire).

\section{. QUINTO - INVESTIGAR!}

"Periferia ou contexto: essas são as novas palavras de ordem da actividade artística que excluem o corpo circunscrito, delimitado, da obra, para promover o espaço que ela habita, suas cercanias. Como qualificar $e$ definir esse movimento de passagem dos corpos para a sua habitação, essa transmissão da aura em presença a uma área em extensão e disseminação?"

CAUQUELIN (2006: 119)

Não se pretende usar o vigor de um manifesto neste artigo, onde apenas se aflora um posicionamento pessoal que ancora o sentido da investigação no devir próprio do professor/artista/investigador. Reconhece-se que a 'investigação em educação artística' assume a urgência de esclarecer o seu devir, afirmando sem exitação depender da sua vinculação ao campo epistemológico e ontológico em que se funde, num processo participativo e amplo. Urgência que se amplia, segundo o autor deste artigo, na insatisfação por a 'investigaçao em educação artística' ainda não ter conseguido libertar-se das amarras académicas, intitucionais e metodológicas da 'investigação em ciências sociais' e da 'investigação em ciências da educação' e aproximar-se dos esforços da 'investigação em arte' para se encontrarem os seus espaços de autonomia e legitimação.

Será preciso ampliar os esforços que se movem na procura da incorporação no 'texto de investigação' de outras linguagens, da legitimação do uso da intersubjectividade e poética inerentes ao artístico e na recusa peremptória de submissão a ditames fundamentados em áreas distintas e que se movem em devires próprios. Esta assinalada urgência fundamenta-se na insatisfação persistente perante o auto-anunciado esplendor dos modelos hegemónicos que asfixiam o exercício democrático de uma prática agonistica 
que conflitue o real e possibilite espaços para um futuro em aberto.

"O bom cidadão, o bom membro da família, o bom trabalhador, a boa pessoa implicam práticas administrativas para moldar e talhar o cidadão."

POPKEWITZ (2011:19)

Insiste-se ainda, nesta ponta final de um artigo que apenas pretende abrir perspectivas de abordagem da investigação em educação artística, na premência de se tornar explícita que a construção de conhecimento se pode inscrever em práticas administrativas, em governamentalidades (FOUCAULT, 1996), ou lhe contrapor procuras agonísticas que tornem desconfortáveis as ideias naturalizadas.

\section{BIBLIOGRAFIA}

AGAMBEN, Giorgio. La Comunitá che viene (1990). A Comunidade que vem, Editorial Presença (1993), tradução de António Guerreiro

AGAMBEN, Giorgio. Nidità (2009). Nudez, Relógio D’Água (2010), tradução de Miguel Serras Pereira

APPADURAI, Arjum. Modernity at Large - Culture Dimensions of Globalization (1966). Dimensões Culturais da Globalização, Editorial Teorema (2004), tradução de Telma Costa

BAUDRILLARD, Jean (1979). De la Séduction, Da Sedução, São Paulo, Papirus, 1992, tradução de Tânia Pellegrini.

BAUMAN, Zygmunt. Wast Lives (2004), Vidas Desperdiçadas, Ediciones Paidós Ibéria, SA (2005), tradução de Pablo Hrmida Lazcano

BRETON, André (1952). Entétiens, Entrevistas, Lisboa, Edições Salamandra (1994), tradução de Ernesto Sampaio.

CALABRESE, Omar (1987). L'Etá Neobarroca. A idade neobarroca, Edições 70, tradução de Carmem Carvalho.

CIEBA (2010). INVESTIGAÇÃO EM ARTE - Uma floresta muitos caminhos, VOLI.

CIEBA (2011). INVESTIGAÇÃO EM ARTE E DESIGN - Fendas no método e na criação, VOL II.

CAUQUELIN, Anne (2006). Fréquenter les incorporels. Frequentar os Incorporais, S. Paulo, Martins Fontes, 2008, tradução Huendel Viana.

DELEUZE, Gilles (2002), Logique de la sensation, Lógica da sensação, Orfeu
Negro, Lisboa 2011, tradução de José Miranda Justo.

FOUCAULT, Michel. Qu'est-ce qu'un auteur? (1969), O que é um autor?, Nova Vega (2006), tradução de António Fernando Casais e Eduardo Cordeiro

FREIRE, Paulo (1996). Pedagogia do Oprimido, Paz e Terra (2004)

HALL, Edward T. (1983) The Dance of Life - The Other Dimension of Time. A Dança da Vida - A Outra Dimensão do Tempo, Relógio D’Água (1996), tradução de Manuel Alberto

HERNÁNDEZ, Fernando (2007). Espigador@s de la cultura visual, Ediciones Ocatedro, Barcelona.

IRWIN, Rita L. (2008), A/r/tografia: uma mestiçagem metonímica. in BARBOSA, Ana Mae e AMARAL, Lilian (org) (2008). Interterritorialidades, mídias, contextos e educação. São Paulo, Editora SENAC e Edições SESECSP

MACEDO, Donaldo (2011). A Democracia Imposta. Diálogos com Noam Chomsky e Paulo Freire, Edições Pedago, tradução de Graça Gami

MOUFFE, Chantal. Prácticas artísticas y democracia agonística (2007). Universidade Autónoma de Barcelona.

MOUFFE, Chantal (1993). The Return of the Political, O Regresso do Político, Lisboa, Gradiva, 1996, tradução de Ana Cecília Simões.

PERNIOLA, Mario (1991). Del Sentire. Do Sentir, Editorial Presença, 1993, tradução de António Guerreiro

POPKEWITZ, Thomas S. (2011). Políticas Educativas e Curriculares. Abordagens Sociológicas Críticas. Edições Pedagogo, Lda.

RANCIÈRE, Jacques (2000). La portage du sensible: esthétique et politique. The politics of aesthetics, Continuum (2004) translated with an Introduction by Gabriel Rockhill

ROTHKO, Mark (2004). The artist's reality. Philosophies of art. A realidade do artista, Edições Cotovia, (2007), tradução de Fernanda Mira Barros

SONTAG, Susan (1966). Against Interpretation, Contra a Interpretação, L\&PM (1987), tradução de Ana Maria Capovilla 